\title{
Production Cultures and Differentiations of Digital Labour
}

\author{
Yujie Chen
}

\author{
University of Maryland, College Park, the United States, chenyj@umd.edu
}

\begin{abstract}
The article makes two theoretical interventions to engage with current scholarship on digital labour. First, the author complicates the relationship between culture and production by bringing the former from the "superstructure" in the classical Marx's framework to the "base." As various cultural production, consumption, and economic activities converging onto digital, networked media ecosystem, digital labour is indeed the indispensable source for capitals' accumulation of surplus and, more importantly, for cultural differentiations of production process. How labourers perceive their relations and interactions to the digital production process is as crucial as which capacity they rely on to perform their labour. Culturalization of production process (re)draws the boundaries for the meanings of labouring and thus is complicit in constructing ideal digital labourers with exemplary, normative social behaviours. Second, precisely because the production process has become normative construction site, meanings and values of labouring are subject to broader social and cultural context beyond the digital realm. Therefore, to further understand the conditions of digital labour, historical global inequality needs to be articulated. Equally important is to investigate emerging cultural discourses which render certain social behaviours in the digital realm as normal and desirable while others as invisible.
\end{abstract}

Keywords: digital labour, discourse, value, data,

Acknowledgement: The author is grateful to the editors of this special issue, the reviewers, and Dr. Jason Farman, who have all made invaluable comments on earlier drafts of this article.

\section{Introduction: big data and digital labour}

Three headline stories in 2012 draw people's attention to the notion of data and its economic and cultural ramifications for work in contemporary age. Facebook Inc.'s \$16 billion IPO in May 2012 exemplifies the complex relations between the value of labour and the information production on the social media in particular and the new media ecology in general. In spite of the dramatic plummet of its share price in the weeks following the IPO, the market value of Facebook as the day of writing (June 2014) -about $\$ 170$ billion-still baffles those who know this number is larger than the combination of the top two PC manufactures, HP and Lenovo, which are worth $\$ 28$ billion and $\$ 9$ billion respectively. Where is Facebook's enormously economic evaluation coming from? In February 2012, Facebook opened its pitch for public trading by presenting four numbers in a diagram in its S-1 registration statement filed with U.S. Securities and Exchange Commission $(2012,1)$ : 845 million monthly active users, 2.7 billion likes and comments per day, 250 million photos uploaded per day, and 100 billion friendships. While the company did not demonstrate how these figures translate into its potential market value, it managed to generate economic significance of these numbers under one category-user data. As the company explained to advertisers, its biggest revenue source, the ownership and manipulation of such a large size of user data, gives the company a "unique" edge to enhance the effectiveness and relevance of their advertisement. ${ }^{1}$ Facebook believes that user data, be it uploaded photos or friendship connections or "likes", express individuals' interests and disclose details about their social relations. By selling the information about users' interests and social relations to advertisers who can then make the advertisements more relevant to the targeted people, Facebook made one billion dollars in 2011. And the economic anticipation shown in its IPO and its concomitant capitalization on

\footnotetext{
${ }^{1}$ Revenue from advertisers consists of $98 \%, 95 \%$, and $85 \%$ of the total Facebook's revenue in 2009, 2010, 2011, respectively. See (United States Securities and Exchange Commission 2012, 11).
} 
the financial market seem to reinforce the logic Facebook embodies regarding the relationship between data, profit, and market value.

Speculations on anticipative value of information and data are not restricted to market capitalization, but expand to political and cultural realms. Early in November 2012, Barack Obama was reelected as U.S. President with a significant margin of the electoral votes. With Obama's victory, his campaign's less well-known team of data analysts stepped into the public eye (Scherer 2012). Obama's campaign team of data scientists has a massive synthetic database which contains pollsters' information, voters' demographic data, voting records, and voters' consumer records, as well as social media activities. Through data mining and predictive analytics, the data science team was able to identify the key concerns in the undecided voters' mind and help President Obama tailor the political ads to get voters' attention and eventually their ballots. ${ }^{2}$ With President Obama's win, a New York Times blogger and a statistician named Nate Silver who was independent of the Obama campaign attracted tremendous media attention. Like what he did with the election four years ago and even better, Silver correctly predicted not only the victory of President Obama ( $90 \%$ chance of win) but also the outcome of the election in 49 states, when the national polls showed, and most politics observers seconded, it should have been a tied race. ${ }^{3}$ Silver's book entitled The Signal and Noise: Why So Many Predictions Fail-but Some Don't (published before the Election Day) soon became a national bestseller. Silver's precise prediction shares President Obama's secret to successful reelection, namely, the reliance on large datasets about American voters and sophisticated statistical models to analyze the data and predict voters' behaviours. Indeed, President Obama is not the first candidate incorporating data analysis into political campaign. Nor is Nate Silver the first ever statistician who applied statistic models in forecasting. For those who still remember, the "electronic brain", a computer named UNIVAC, was first introduced for election coverage in 1952 presidential election. But the purpose was more to seize the public imagination of computers than actual adoption of computerized prediction (Chinoy 2010). When it comes to political analysis, UNIVAC fell out of favour in the following mid-term election in 1954 and was replaced by human brains.

It took six decades for the mainstream media to finally embrace the power of big data in political forecasting, which seems to be a long overdue justification for a technological turn in the narratives around the presidential election. Nonetheless, President Obama earning the title of "big data" president and big data being singled out as the most identifiable characteristic for 2012 election reveals something deeper about the shifts in cultural attitude toward data and the scope of the fields to which data analysis can be applied. ${ }^{4}$

Along with creating a popular tech-savvy icon out of Nate Silver as "the data wizard" (Hurwitz 2012; Casaretto 2012), some reporters declared that we are entering a new political era, "where data scientists have pushed out the [...] experts" and where hard data proves the invalidity and obsolescence of "political instinct" (Vos 2012; Scherer 2012; Horsey 2012). Several months after the Election Day, Wired magazine speculated on the success formula for the next U.S. president in 2016 as "Big Data + Social Data = Your Next President" (Chahal 2013).

Facebook's IPO, Obama's reelection, and Nate Silver's mythical prediction based on manipulation of massive data and statistical simulations make "big data" one of the most significant terms in economic, political, and cultural expressions.

The problem is, however, there is no consensus on almost any specifics regarding the term big data, from the definition and connotation of the term, to the scope and measurement

\footnotetext{
${ }^{2}$ Data mining refers to a set of data analysis techniques used to discover unknown patterns or correlations among various variables in the given datasets. Predictive analytics are typically defined as the analytics, built upon correlations found via data mining and computerized simulation and modeling, which are used to predict the possible future outcomes so that companies can plan future strategies accordingly.

${ }^{3}$ For more on Nate Silver's blog at New York Times, see http://fivethirtyeight.blogs.nytimes.com/

${ }^{4}$ Data and information are defined differently in the field of information management and computer science, as the former is considered as the base unit for the latter and the latter occupies a higher position in the knowledge production hierarchy. I will return to the difference in the later chapters. For an excellent critique of this hierarchy (Weinberger 2012).
} 
methods, and implications of big data. Nor is there any agreement on how large a dataset or the accumulative amount of data can be considered as "big". The term big data means different things, refers to different contexts, and implies different consequences depending on who deploys the concept. It indicates a cultural trend that involves interplays of technology as well as unfolding myth-construction which promotes faith in quantification and associate quantification with absolute neutrality, objectivity, and truth (boyd and Crawford 2012, 663).

When Mark Poster (1990) examined the implications of electronic communication technologies, he suggested to expand the scope of analysis to "the mode of information"-the cultural experience of the subject, which is configured by new technologies but subject to more possibilities. As information has been elevated to a new level of cultural privilege in the 1980s and 1990s, remarkable discourses around (big) data and pervasive discussions on the implications of big data thus require serious scholarly examination into the mode of data, and more importantly, the role of digital labour in the process of data production.

While it is urgent to have scholarly conversations on digital labour in the fields of new media culture and critical studies of contemporary society, there are several practical and analytical obstacles to theorising digital labour. These obstacles derive from common misunderstandings around digital labour. Nonetheless, leading multi-national companies are committed themselves to instilling these misunderstandings into the society to conceal the way in which digital labour is appropriated for value generation and profit making.

Misunderstanding \#1: "It is fun and it does not feel like work at all." Users of social media like Facebook are producing their personal data for the company, but are they workers for Facebook? Since Facebook does not pay their users for disclosing and sharing their personal information, is it legitimate to describe users' work for Facebook as being exploited or as "free labour"? When Arianna Huffington sold Huffington Post, a blogosphere where freelancer columnists contribute on a voluntary basis, for $\$ 315$ million to $\mathrm{AOL}$, the transaction ignited furious protest from volunteer columnists and online fair labour activist groups. They demanded financial compensation for the bloggers' voluntary work for Huffington Post. In sharp contrast, Facebook's IPO encounters nearly zero protest from its users and labour union organizers, although the former build the Facebook social media empire in almost the same way as freelancer columnists did for Huffington Post. Lack of protest for financial compensation in the case of Facebook can partially be attributed to the experience with social media that, as Trebor Scholz $(2012,2)$ describes, "[it] does not feel, look, or smell like labour at all". In addition, joining Facebook and utilizing social media is optional. The fact that it is optional and not obligatory implies certain degree of autonomy on the part of Facebook users. At the end of the day, they can opt out and stop using the social network site any time they want. This feelings of autonomy is part of the reason for interactions on the social media site to not be felt like labour at all. Statements like "it is voluntary and it is fun so it should be considered as work" misunderstand the relationship between labour and work. What constitutes labour in the digital realm becomes elusive. Nowhere is the elusiveness of the characteristics more visible than the flood of newly emerged scholarly vocabularies to describe the feature of labour in the digital world. Digital labour, cyber coolies, free labour, immaterial labour, cognitive labour, creative labour, knowledge workers, collaborative labour, crowd-sourcing, micro work, and playbor, and the list continues. Various adjectives before the word "labour" attest to scholarly desires and efforts to make sense of the changes information and communication technologies (ICT) have brought to not only the working environment and labour organization, but also the content of work and the nature of working in the mediated environment.

Misunderstanding \#2: Marx's labour value theory is obsolete. Whether social media users' labour is the sole creator of the value of their data as well as Facebook's profits, as Karl Marx might argue, turns out to be a perplexing question. For instance, Adam Advidsson and Elanor Colleoni (2012) contend that Marxist labour theory of value is obsolete in explaining the value creation of social media companies and their relationship to social media users. For the market value of the social media company is determined more by financial market speculation than the productivity and inputs of their users. Furthermore, users' affective investment in maintaining their social interactions via social media platforms cannot be measured by (labour) time which Marx reckons as the single determinant in how much value is created. As 
the company's S-1 form and stock performance evidenced, however, the value of Facebook is largely dependent on the speculations of the potential profits the company can make out of the massive user data.

Misunderstanding \#3: digital labour is immaterial and thus bodiless which has little to do with geographical and temporal barriers. If we take a closer look at Nate Silver's day job and President Obama's team of data scientists, polling information and other social data about the voters certainly constitutes the "raw materials" for their work content. Given the reliance on the data-processing technologies and expertise in statistics and computing modeling, information is both the raw materials and the means of production. Indeed, the source of the data has little to do with the location of these peoples' workplace. As long as they have the access to the Internet and the databases, they can perform their work anywhere they want. However, a division of labour is set in motion between specialized data analyst (and scientist), which Silver represents, and less visible data producers such as Facebook users and millions of consumers who feed into database their social interactions, consumption patterns, political tendencies, and so on. This division of labour is also intimately tied to a bifurcated reward mechanism, symbolically and financially. While the former represents members of "creative class" enjoying public attention and transcending occupational boundaries, the latter is absent from the grandiose narrative about the future of big data and rendered as invisible in data production process. ${ }^{5}$ This misunderstanding greatly distorts the reality of digital labour in the form of data production also because social activities such as consumption habits and online interactions which are coded as data in the social media system largely reflect and/or expand what they are like in the offline world (Rainie and Wellman 2012). The offline world is subject to geographical inequalities which causes the gaps in the Internet access.

Along with Trebor Scholz's aforementioned comment, what should labour "feel, look, and smell like" in the digital age of big data? If user data are the product Facebook is selling and capitalizing upon, how can we delineate the process and to what extent is users' perception of their relationship with Facebook representative of the forms of digital labour? Given Nate Silver's hypervisibility and era of celebrity, what kind of power mechanism is at work to determine the degree of the visibility, earnings, social status, and cultural significances of different types of digital labour?

Digital labour throughout this article is defined as the part of interactions with digital communication devices, which have been appropriated for profit making. This definition differs from conventional concept of work in that it describes more fragmented and ephemeral encounters with digital, networked online environment, which may or may not be recognized as conventional work.

The goal of this article is to further dismantle the aforementioned misunderstandings of digital labour. In the following sections, I will propose the theoretical groundwork to analyze digital labour by establishing connections among the categories of "data", "value", and the notion of "labour". My argument is that we need a discursive-material approach toward analyzing the cultural differentiation, valorization, and the organization of digital labour. It needs to focus on discursive formation as certain activities and online behaviours, which are deemed as not related to work, have been appropriated for private company's profit making. As we migrate more and more social interactions onto the online space and most of the online activities are coded into data forms unknown to us, the line between the social and the economic starts to become blurring. Latest discourse around the value of (big) data which renders labour embodied in the data production invisible shift the definitive boundaries of what needs to be considered as labour in the first place (section 2). One of the most profound implications of challenging dominant discourses around data and value is to make otherwise invisible digital labour visible. In section three, along with analyzing the aforementioned three misunderstandings of digital labour as the key examples of how discourses work, I will focus on discussing the materiality of digital labour. Labour is almost always em-

\footnotetext{
${ }^{5}$ While as data producers, most of the Internet users are invisible, as targets for surveillance and victims for privacy violation, they are hyper-visible (even more so after Edward Snowden's revelation of NSA's surveillance program). Mark Andrejevic (2012) argues cogently that theoretical framework and social advocacy based on privacy as an inalienable right fall short to capture the whole picture of the political economy of data production.
} 
bodied. Labour division is associated with social stratification and cultural differentiation. Without addressing both the discursive formations surrounding data and value and the implications of discourses for the valorization, circulation, and organization of labour, scholars would find it difficult to critically understand digital labour in the informational capitalism as well as in the age of big data.

\section{What can we learn from discourses around value and (Big) Data about Digital Labour}

Due to information and communication technologies (ICT) developments like the computer, Internet, tablets, and mobile phones, the collection and dissemination of information has become more abundant and data gathering comes from almost everywhere in today's world. Information exchanged on the Internet is considered as a significant resource for economic production and indispensable component in people's daily life. International Data Corporation (IDC) predicts a 6.9 per cent increase in worldwide IT spending in 2012 while the projection of the global gross domestic product (GDP) growth is set at 2.5 per cent by the World Bank (IDC 2011; The World Bank 2012). An average daily consumption of 34 gigabytes of information in 2008 shows the crucial position of information in Americans' daily life (Bohn and Short 2009). To put this number in a more meaningful context, a three-hundred-page dissertation stored in portable document format (PDF) and a popular song in MP3 format is about 4 megabytes. The size of a DVD movie varies from 2 to 7 gigabytes each. Since one gigabyte equals 1,024 megabytes, it means in 2008 the average American's information consumption could be anywhere from 256 dissertations or songs to 5 DVD movies per day. In addition to consumption, the pace to produce information is also unprecedented, and information production does not restrict to information technology industries. For instance, Walmart, world retailer industry leader, has to handle more than 2.5 petabytes of data generated from customers' transaction per hour. That is equivalent of 167 times all books in the U.S. Library of Congress (The Economist 2010). Juan Luis Carselle (2013), the former chief information security officer at Walmart South America, points out that Walmart is now an IT company that also does retail.

McKinsey Global Institute $(2011,15)$, a research firm affiliated with McKinsey \& Company, estimated that the information produced and stored by global companies and individuals in the year of 2010 exceeded 13 exabytes, which is 60,000 times larger than the amount of information U.S. Library of Congress stores.

Indeed, information has been assigned with increasing social and cultural significance. Nonetheless, the job of number-crunching clerks or book-keepers was once pictured as monotonous, dispiriting, and a "sorry example of the ongoing massification of modern life" in many literature and popular imaginations (Roszak 1987, 5). It is intriguing to juxtapose this past pathetic image to the tech-savvy, brilliant, and creative figure of statistician embodied by Nate Silver. What is omitted from the attitudinal shift is the fact that the content of their job is pretty much unchanged, namely, making sense of abstracted numbers. The most visible characteristics which distinguish Nate Silver from his occupational predecessor are the amount of data he is analyzing and the fields where he applies the meanings of the numbers. In a very similar gesture, Facebook boasts about the amount of data they are holding on their users, and see those data as the unique assets of the company.

The pure, mathematic reasoning originated from modern information and communication theories has successfully expanded to the social and cultural realms. Scholars and advertisers have developed "trust in numbers" (Porter 1995) and relied upon quantitative analysis for analysis and predictions for decades. What distinguishes the present moment from the past usage of quantitative data is the extent to which new categories of data are invented to describe and measure socio-psychological behaviours, physiological motions, and even sentimental ups and downs. Facebook's knowledge about its users is far beyond basic profiling information and aggregated social interactions data. Through built-in algorithms, Facebook also knows its users' "pace of life", "concentration cycle throughout the day", "preferences between text, photo, and video", "logical thinking", and "the degree of happiness" to name a 
few (Olsthoom 2013). The source for these "knowledge" is a huge engineering project which codes people's social connections and desires as peculiar types of data manageable and manipulable by computers.

Nonetheless how engineers develop viable interpretations of users' Facebook data as indicators for "the degree of happiness" remains unknown to the public. One thing is crystal clear-the power relations between those who set rules for the definition and interpretation of the data and those who produce data are opaque and asymmetric. Andrejevic $(2012,84)$ pinpoints the asymmetric power relations embedded in the commercialized model of the Internet infrastructure, that is, operative in the hands of private companies. As people rely on the Internet to perform more and more activities from getting news and information to interacting with friends and engaging in communities, the Internet infrastructure becomes increasingly constitutive of tens of millions of people's social reality. However, for platform-provision companies, the Internet infrastructure indeed becomes "material resources" for economic profits while for Internet users the Internet is the place for a variety of social and cultural activities.

This functional conflation alerts us to confront the social and cultural ramifications of economic activities based on constructed value of information and data, and how exactly value and labour are defined in those economic practices. To better understand how value of data and labor are socially constructed in the informational capitalism, it is important to first set the concept of the economy back to the social which is subject to discursive formations.

Economic activities are historically specific and should always be understood as "embedded" in the society at large and in the complex social relations and cultural practices. Timothy Mitchell (1998) suggests that the concept of the economy is a recent idea which dated back to the mid-twentieth century. Over the last half a century, scholars and national policy makers jointly constructed and "modelled the economic process as a mechanical apparatus" (Mitchell $1998,86)$ which gradually appeared to detach from the social forces. Karl Polanyi (2001) is perhaps among the first few thinkers who cast skepticism on the naturalness of capitalist market economy and deconstruct the liberal creed of autonomous market as a discursive and social construction. Back in the mid-20th century when political economy theorists were engaged in heated debate on the necessity of governmental regulations in the realm of free market, Polanyi $(2001,3)$ argues that autonomous market economy is historically proved non-existent and liberal economist's belief in laissez-faire is "stark Utopia" and groundless. Prior to the emergence of free market, economic exchanges and market activities, for instance, in the customary practice of barter, were largely rested upon social connections and local communities. The inception of capitalist market economy was not a natural outcome of local markets converging into a national and international one. On contrary, the imagined autonomous market is constructed along with vocal advocacy for free competition, rather violently economic endeavor to expand trade from Europe to across the planet, political lobby for tariff protection and governmental regulation. While lobby for tariff protection and trade expansion is coming from elite business interest groups, often overlooked grassroots resistance which is behind the forces for government regulations is from the mass individuals. Public resistance does not come from intuitive hatred toward market or orchestrated conspiracy against the spread of transnational trade. On the contrary, the construction of autonomous market disregards the deeply rooted, long-term daily practice and social relationships in which individuals make sense of their economic activities, and attempts to subjugate the former to the latter. Public resistance originates from the disruption caused by the sweeping market economy of individuals' habitual daily practice and social relations.

Polanyi's recount of the interplays between the liberal discourse of free market and the economic practices rooted in the networks of social relations, together with his thesis on economic embeddedness in the broad social context, indicates that the boundaries around the economic realm are porous and socially constructed. The line between the economic and the non-economic has been drawn and redrawn throughout the history. Take Facebook as an example again. Several scholars consider the social media giant's worldwide popularity as the ultimate triumph of capital's "real subsumption" of every bit of social interactions and relationships for Facebook users' activities constitute the very informational infrastructure 
and online environment they are inhabiting (Dyer-Witheford 2004; Fuchs 2011; Fuchs 2010). While this kind of criticism pinpoints the economic engines behind the Internet companies such as Facebook, it glosses over the way in which those companies redefine what constitutes economic practices and relations and what are redefined as the non-economic ones. Indeed, discussions on social ramifications of the line redrawn beyond economic exploitations of the Facebook users are nowhere close to the easy resort to the Marxist mode of economic criticism.

The point, however, is not to discard a closer scrutiny of Facebook's profit-generation strategy. Rather, it might be more productive to put its profit-generation strategy within a broader social context and consider what has been redefined as economic activities and what has not. Keep in mind this scenario: when asked on his stance on the privacy issue in early 2010, Mark Zuckerberg (2010), the CEO and founder of Facebook, responded that "[people] have really gotten comfortable not only sharing more information and different kinds, but more openly and with more people...We (the Facebook) view it as our role in the system to constantly be innovating [...] to reflect what the current social norms are...We decided that these would be the social norms now and we just went for it". The social norms Zuckerberg claimed as he and his company detect are exactly the social behaviours and activities they encourage Facebook users to do and perpetuate as the norm. Investigating how social norms around information and data have evolved and been constructed by a cluster of players including Facebook is just as important as disclosing Facebook's reliance on users' shared information for economic profits.

Value is never a pure economic term it almost always has social and cultural register. Oxford English Dictionary documents, besides being quantitative measurement of the material worth of something, often used as the medium for market exchange, value also refers to "worth based on esteem; quality viewed in terms of importance, usefulness, desirability" (Oxford English Dictionary 2013). While social worthiness and desirability has a lot to do with the broad cultural discourses and historical circumstance, they are not immaterial. On the contrary, social desirability and worthiness are established largely upon material practices such as possessions of certain symbolic and substantial goods or the construction of social hierarchies which directly determines the distribution of social, political, and economic resources.

All these entail a material-discursive perspective to look at the information-based economy and labour issues. As cultural studies theorist Lawrence Grossberg urges, we should recognize "that economies are partially discursive [...] [and] completely integrated into the social totality" (Grossberg 2010, 102).

The power of technological discourses in particular takes effect in material forms. Since the invention of scientific management and Fordism way of manufacturing, there are few doubts about technologies' effect on division of labour. However, few notice that technological division of labour can hardly separate from social construction of differentiation among labour types. For instance, the constructed division between women's domestic labour and men's productive labour was tied to the fact that women were paid nothing for the fulfillment of the reproductive labour. And their domestic labour was theorized as unproductive and immaterial making little contributions to economic development. Even if technological advancement and social improvement allow women to step out of home participating in traditionally productive sectors, a "gender-segregated" labour market is awaiting (McRobbie 2011). As a result, a majority of women found themselves concentrated in certain subordinate or feminized occupations such as office clerk. The social hierarchy regarding women and men's labour also involves a spatial division between them which designates the home space to women and public sphere men. I will return to the point on the social and spatial division of labour later.

Along this line, as Zuckerberg tried to dissolve the line between the economic and the social, his claims remind us of how discourses work to construct the line between productive and unproductive labour. In his framework, the social norms are widely accepted social activities (not to mention Facebook's own role in creating the social norms in the first place) which should not be considered as productive since productive activities translate into monetary rewards. By expanding the scope of acceptable online social activities and creating new so- 
cial norms, Facebook and Zuckerberg attempt to redraw the boundaries of being productive or unproductive. Therefore, to thoroughly understand this type of digital labour, ideologies deployed to construct what are socially desirable and acceptable need to take into consideration.

Admittedly, social media users as the sole producers of their social data, their labour is creating the value of those data. However, their data world be worthless if it were thirty years ago when the constructed value of data have not reached the current level. Consequently, it would be meaningless to analyze the value and organization of labour unless situating it in the concrete social, material conditions which are already mediated by cultural discourses. Social differentiations of working bodies (as in the case of men and women) are inseparable from spatial rearrangement of labour division. As this article aims to engage with scholarly conversations on the value and organization of labour in the network society, it is necessary to tease out the threads from the "contextually determined set of material-discursive apparatuses" (Grossberg 2010, 102), which shape our perceptions of the social worthiness of information, the value of labour related to information (from producing to processing to dissemination), and socio-geographical division of labour. Thus, interrogating dominant ideology and rhetoric around work in the information age is foundational to understanding the differentiations of digital labour.

\section{Is digital labour immaterial? The materiality and differentiation of digital la- bour}

Technological discourses surrounding information and labour in the informational network society acts on material basis. In this section, I will mainly dismantle misunderstanding \#3 around digital labour. Namely, nothing is further from the truth than to regard digital labour to be immaterial. The bodily foundations for labouring activities and the materiality of labour are reflected in the interplays among human bodies and information and communication technologies (ICTs) within the social and cultural context. Two dominant forces are noteworthy. The first is capital's constant tendency to make labour invisible in the form of commodities and service. The second is hegemonic ideologies rendering bodies as obsolete in informational and network society, which further distance labouring bodies from our range of vision. Moreover, to recognize bodily materiality of digital labour is crucial also because labouring bodies are the sites where social differences are constructed and spatial divisions are formed.

\subsection{Make invisible labour visible}

Karl Marx's criticism of commodity fetishism is one of first eloquent accounts to identify capital's tendency to invisiblize labour. Marx (1995a) opens Capital with a discussion on commodities, but he directs the readers away from the marketplace where commodities are exchanged to the production site. His real intention is to demystify commodities as inherently valuable and naturally exchangeable goods. Focusing on the production site, Marx argues that commodities are able to circulate on the market because there is something commensurable and common in all commodities despite their varied utilities. And this commonplace is the embodiment of human labour. To unveil how labour is extracted to create value and wealth, Marx identifies the dual-character of labour as being both abstract and concrete. While abstract labour reflects the universalized, interchangeable nature of the expenditures of human bodily practice, concrete labour has to do with the specific subject, raw materials, and instruments in the labouring process. Abstract labour creates the exchange value of the product; concrete labour shapes the utility of certain products, namely, the use value. Both value and use value of commodities are the embodiments of labour. Commodities production site is where labour is turned into the value and where labour is materialized. Commodities are the objectified labour, but at the same time they make labour invisible.

Writing at the dawn of industrial age, Marx already saw, and anticipated more, technological applications into production. He considered massively applied science and technologies as the objectified labour in the forms of tools, instruments, and machineries in the industrial age, and perhaps including today's automated systems. He described machinery as "the 
body of factory" and the stored-up labour in tools and instruments as "dead labour" (Marx 1995b). Thanks to the technological development, capitalistic productivity grows at an exponential rate, relying less and less on the operative labour at the machineries and more and more on the productive tools and instruments (read dead labour). Since capitalists hold the private ownership over tools, instruments, and machineries, it appeared to Marx that the objectified labour taking various shapes (including commodities and tools) eventually would dominate the living labourers who oversight the automated systems. In this way, capitalists' social dominations over wage workers are enhanced and naturalized in the "technological fact" (Marx 1861). Again, the dead labour in forms of technologies, knowledge, and tools and instrument are rendered invisible and independent of, if not alienated from, the contemporary workers. Marx's line of reasoning and endeavour is endorsed and persistently pursued by generations of succeeding scholars. For example, Kathi Weeks $(2011,7)$ protests the oblivion to the central role of work in our current daily life. She sees publicizing work's foundational role is the first step to politicize it and "to counter the forces that would naturalize, privatize, individualize $[\ldots]$ and $[\ldots]$ depoliticize it."

While Marx's focus of study remains at the production site, namely, manufacturing factories, capital's accumulation thrives upon appropriations of activities in the non-production fields where work exists in forms other than wage labour (De Angelis 2001; Huws 2003; Prodnik 2012; Terranova 2000; Virno 2004). The existence of those unrecognized forms of labour challenges Marx's labour value theory since performed outside production site those unrecognized labour is most likely embodied in the forms like service rather than commodities. In addition, the value of various forms of unrecognized labour is subject to social and cultural forces other than marketplace exchange mechanism. Nor can they be measured by the amount of "socially necessary labour" used to produce it, as Marx proposes.

Several scholars have proposed expansive definition of commodification and tactical understanding of work to more accurately understand the relationship between those parasite activities and standard occupational labour. Ursula Huws (2003, 67), for example, defines labour performed outside the standard commodification process as "unsocialized labour". The ongoing commodification constantly affects the forms and scopes of labour that is not yet incorporated into the capitalist cycle of accumulation. The boundaries between unrecognized labour and relatively more standardized forms of labour are porous and keep shifting under the circumstance of capital accumulations. Once the border shifts, the scopes and forms of unsocialized labour change accordingly, which in turn affect the established pool of standard work. Technologies are always deployed to facilitate changes in the scopes and forms of labour. Some skills are rendered obsolete by technologies, new skills are demanded, and still others revive after a period of disappearance. In the rise and fall of certain labour, we notice shifted boundaries are accompanying spatial divisions for the labour and discursive constructions of differences for the bodies that perform the unsocialized labour.

Women's unpaid domestic labour, for instance, is among the first unsocialized labour that was subsumed by capitalist economy. And home appliance is one of the earliest examples of capital's tendency to replace unsocialized labour with massive manufactured commodities and/or paid service provision (Huws 2003; Fortunati 2007). Thanks to technological development, all kinds of home appliances are manufactured. Home appliances are promoted as liberating women from tedious housework with the latter often relegated as outside productive domain and without value. The grandiose mission to replace women's reproductive labour seems to have failed; the one to turn the home space into another market for machinzed goods and standardized service have succeeded. Unfortunately, commercial promotion of home appliance's efficiency conceals new forms of women's reproductive labour, such as operating home appliances and communicating with technicians to maintain the home appliance (Fortunati 2007).

The concept of immaterial labour is also introduced to capture new content of work and the shifting line of labour. As James Beniger meticulously documents, how to improve information processing and communication technologies (ICT) first appeared as an urgent challenge in late 19th century and early 20th century (Beniger 1986). During that period of time, innovations in ICT were badly needed because industrial revolution led to massive reproduc- 
tion of goods and the information concerning inventory and business transactions exceeded the contemporary processing capacities. Information processing capacities prove to be the bottleneck for full realization of manufacturing productivity. Since then, especially in the United States and other developed countries, workers increasingly rely upon their subjectivity and knowledge to fulfil their jobs; and their work content has more and more to do with information, communication and coordination rather than direct contact with manufactured goods. To readdress the composition of wage workers in post-industrial capitalism and the role of workers' subjectivity in processing information to create value, Maurizio Lazzarato (1999) first introduced the concept of immaterial labour. He defined immaterial labour as what produces "informational and cultural content of the product." Informational content consists of the service and the knowledge labourers provide to the customers with respect to the processing, control, and exchange of information in both manufacturing and service industries. Cultural content includes cultural knowledge on norms and customs, aesthetic tastes, fashion and artistic judgment, and affections.

Similarly, Hardt and Negri $(2001,290)$ in Empire used the concept of immaterial labour to describe service (production) industries because "the production of service results in no material and durable good [...] that is, labour that produce immaterial good, such as a service, a cultural product, knowledge, or communication". They further fleshed out three sub-types of immaterial labour activities. The first involves information processing, such as entry-level word processing and electronic inventory keepers; it typically appears when computers are widely applied in manufacturing industries, realizing the shift from commodity production to service provided as goods. The second is engaged with the creative and/or mechanical manipulation of signs and symbols, such as graphic designers and routine web maintenance workers. The last type of immaterial labour requires personal affective contact and interactive communications, which is also known as affective and communicative labour. Customer service providers and maids are among the third sub-type of immaterial labourers.

Indeed, the idea of immaterial labour greatly advanced our understandings that social relations and cultural, ideological environment are embedded in the social production and continuously reproduced through capitalistic economic reproduction. The notion also substantially reframes the approach to labour-value relationship by extending the parameter of value to the social realms. In this way, we are able to disclose what "material production had 'hidden', namely, that labour produces not only commodities, but first and foremost it produces the capital relation" (Lazzarato 2011). When communication networks increasingly converge with social networks and transnational corporation's networks of suppliers from all over the world, traditional non-working space and time become the new territory for value creation. It is hard to tell where the cycle of immaterial production begins and ends, when social relations, workers' subjectivity, cultural and ideological environment are all reckoned as "raw materials". The elusive nature of immaterial labour deeply troubles Marx's equation between value and labouring time. As a matter of fact, the content of the work and the extraction of labour can be nearly anything as long as capital accumulates.

Another prominent example of how technologies are manipulated to trigger changes in labour forms is the construction of consumer's role in the production cycle in the U.S. pervasive customer self-service in U.S. nowadays has demonstrated the triumph of the steady trend to put consumers to work in 20th century. In this steady process, the boundaries of labour have been shifted from paid service workers to consumers; meanwhile we also hear new words to define the role of customers and thus the forms and meanings of their labour. Marketing and management professionals have been encouraging consumers' (voluntary) participation into production by promoting the latter's creativity and contributions with the label such as value "co-creation" and "consumer-led design" (Prahalad and Ramaswamy 2004; Lovelock and Young 2011). When it comes to Internet users on open, interactive, collaborative platforms such as P2P platforms, Wikipedia, Myspace, and Facebook, terms like "produsers", "prosumer", mass collaboration and cloud collaboration become buzzwords to 
describe Internet user's activities. ${ }^{6}$ The rationale is that web content are produced and consumed simultaneously by massive anonymous Internet users without any charge or payment. Some scholars argue that conventional understanding of production as distinct from consumption from the industrial age seems inapplicable to prosumer-created web content. For the latter represents the non-monetary spirit of sharing which makes it qualify for a fundamental alternative to market- and proprietary based economy, or at the extreme end, a new imagination of capitalism (Bruns 2008; Benkler 2007; Bauwens 2011; Ritzer and Jurgenson 2010; Graham 2011). Others believe that the prosumer metaphor blows the work of a slim percentage of Internet users out of proportion (Van Dijck and Nieborg 2009). The overgeneralization of all Internet users as equally active and motivated and making equal contributions ignores those who literally work online such as Amazon's Mechanic Turks. The metaphor of prosumer society also seems to conceal the value extraction by promoting a particular way of online engagement.

Through the examples of YouTube, Wikipedia, Google, and most recently Facebook, we clearly see the power online interactivities have unleashed from Internet users (among them prosumers). It shows great potentials for future social development, too. Meanwhile we also see the continuity in garnering unrecognized labour for value and surplus production in the course of (re)defining the role of consumers and Internet users. Take Google as an example. Its algorithm, PageRank, is created to order the value of webpages by measuring the number and the quality of incoming links. The more incoming links are and the better quality, the more significance a webpage is. PageRank allows Google to tap on every single cognitive decision made by Internet users in clicking the hyperlinks. Users' cognitive labour contributes to the value garnered by Google (Pasquinelli 2009). Their contributions are naturalized not in the form of commodities but built into the online navigation system structured by algorithms like PageRank and Facebook's default setting for disclosing user's information. Different from Marx's point on living labour in the factory enacts on the dead labour concealed in the machineries, Internet online activities are much alive and constitute the very "technological fact". As part of technological infrastructure, users' labour becomes not only invisible, but also ephemeral yet perpetual in value-creation.

Prosumers' labour is not new, and Internet economy has a long tradition of appropriating non-standard forms of labour, ranging from violent exploitation of volunteer's labour to "anarcho-communism"-spirit of sharing (Terranova 2000; Postigo 2003; Barbrook 2007). It is too hasty to conclude if prosumers are the protagonist of the network society and their social significance can rival that of producers in the industrial age and consumers in the postindustrial age. Conscious construction and recognition of prosumer's place in the Internet structure, nonetheless, allow us to be more aware of the shifted boundaries and forms of labour on other realm than the Internet. In sharp contrast, manual labour in the electronics manufacturing industries are almost complete absent from the dominant discourses around online digital culture. Take assembly line workers for digital devices as an example. Manufacturing workers are facing numerous challenges including low wages, excessively long work hours, severe work conditions, constant harms on health, and hostile political environment which prevents them from forming labour union. As Sandoval's (2013) analysis of Apple Inc.'s responses to criticism of its supply chain management has shown, Foxconn workers are excluded from the hi-tech, clean, sleek image Apple, Inc. aims to create. Instead, the statement from the most profitable IT company deflects its responsibilities for poor work conditions and multiple suicides committed by Foxconn workers. Only when these cheap labourers are faded into the shadows, becoming invisible, then the aura of sleekness and cleanness that Apple devices represent can successfully take root in the digital culture.

Along this line, an intriguing new territory for informal labour activities is in online virtual games. For some U.S. based cultural critiques and intellectuals, the global popularity of virtual environment, including massively multiplayer online role-playing game (MMORPG), signals a new form of sociality where virtual leisure is intertwined with real life social interactions

\footnotetext{
${ }^{6}$ The term prosumer is first used by Alvin Toffler in The Third Wave, but it starts to gain momentum in recent years because of the rise of users-generated content on the Internet.
} 
(Boellstorff 2010; Castronova 2006; Corneliussen and Rettberg 2011; Nardi 2010; Turkle 1997). While game playing always implies fun and leisure, in MMORPGs player labour is harnessed to produce economic value. The feelings of play and fun often obscure the fact that play is labouring (Yee 2006). A transnational hierarchy of labour division seems to form when 100,000 Chinese players are recruited to work on the game producing in-game currency so that their American counterparts can purchase the in-game currency acquiring new weapons and enjoying the pleasant synthetic experience (Lehdonvirta and Ernkvist 2011). However, as Chen (2013) argues, Chinese MMORPG play workers are "double marginalized" in the construction of digital gaming culture across the Atlantic. In the American cultural context, they are rule-breakers, "illegal immigrants" who destroy the fun, non-financial atmosphere of online gaming community. On the other hand, in the Chinese cultural context, playing online games is historically associated with problematic youth who lack self-discipline and suffer from Internet addictions. Under this circumstance, the value of digital labour in the case of online game playing is inseparable from the ongoing construction of gaming cultures.

\subsection{Make differentiated labouring bodies visible, immaterial labour material- interrogating normalization of digital labour}

The notion of both immaterial labour and prosumer each defines the feature of labour with the reference to the final product, although the former tends focuses on the added content of the product or service and the latter on a blended production and consumption behaviours. So far both presumes the working bodies as a given without questioning which forces bring them to the kind of labouring activities in the first place, let alone recognizing the differentiations within the same labour category.

Part of the reason for the absence of bodies is that information, and to the same extent informational labour, is often seen as without materiality. The concept of immaterial labour in particular tends to reduce the material to the tangible; and the information, culture, symbols, affection, and feelings are intangible and thus immaterial. Tiziana Terranova (2004, 3-6) singles out "two prejudices" preventing us from fully capturing the materiality and physicality of information, namely "the idea that information is the content" of messages or communication and the notion that information as code exists immaterially in cybernetic space. Information is not formless, bodiless code floating in the cyberspace. On the contrary, not only are information flows shaped by their material media infrastructures and systems, but also the meaning it conveys is to a large extent constituted by that materiality.

A third hindrance is that modern information theories and bioinformatics have caused an epistemic shift which treats human bodies a medium for signal/information transmission, storage, retrieval, and processing, no differently from other media (Hayles 1999a). Thus the missing link I suggest to put back into the picture is the bodily foundations for informationrelated workers. It requires us to centre upon working bodies and acknowledge bodies as the contested sites for cultural inscriptions and potentially subversive articulations. In doing so, we can make sense how the shifted boundaries of labour in the network society associate with social construction of different labour types. The starting point is to unpack the interactions between labouring bodies and communication tools and media.

Elizabeth Grosz (1994) explained how human is able to use tools in general:

Part of the difficulty of learning how to use these implements and instruments is not simply the technical problem of how they are used but also the libidinal problem of how they become psychically invested [...] It is only in so far as the object ceases to remain an object and becomes a medium, a vehicle for impressions and expression, that it can be used as an instrument or tool (Grosz 1994, 80; Lupton 2000).

These embodied extensions of physical strength, motions, emotions, expressions, and cognitive ideas constitute the materiality of interactions between bodies and the medium. Bodily interactions and mental investment help humans convert the tools in hand (and later on machines and computers) to be part of human bodies or the extension of bodily senses and intelligences (Hayles 1999a; Lupton 2000; Thrift 2006). Boundaries between human bodies 
and tools as objects collapse at the moment when human bodies incorporate the tools into bodily coordinate motions. In labouring, the constant interaction between human bodies and the immediate environment of tools, language, interfaces, and media forms an embodied working environment. The intimate relations and interactions between human and technologies not only constitute the material in the global network society, but also add complexity to the already existed mechanisms of divisions, differentiations, and exclusions.

Labouring bodies are the ultimate actors who interface with the devices making sense of the information and initiating communications. Walter Benjamin (1936) presents a convincing account on how massive reproduction of art occur concurrently with the rising desire from the mass to kill the social distance between the privileged and their mundane life by dislodging subsume elements symbolized in the forms of classical arts from their authenticity and originality. In a similar manner, instantaneous communication via interfaces like computer screens and mobile phone pad has profoundly transformed the interactive dynamics between workers and their clients. Mark Poster argues that the fixed cultural identity categories, such as nationality, in the network society are losing their currency. He also shows that contemporary cultural conditions which have been fundamentally transformed by digital/information technologies are materialized by an intimate hybridity of human and machines, or in his words "humanchine" (Poster 2001; Poster 2004, 318). In Poster's eyes, "humanchine" is subject to dominant politico-economic powers and other social trends but simultaneously emerges as the new contested sites of resistance and empowerment. Scott Lash $(2002,15)$ also proposed a "man-machine interface" as an entry point to understand life experience in the informational and technological society. Although Lash insisted that it is an interface rather than cyborg or any forms of fusion, both Poster and Lash implied that bodies are indispensable for the materiality in the information technologies. Hayles (1999b, 193-207) argued that a new kind of "subjectivity" emerges from constant interplays between normative and disciplinary forces from dominant culture inscribing upon bodies and embodied articulations from culture-specific, environment-sensitive experiences. Indirectly echoing Benjamin's elaborations on the relationship between historical circumstance, medium, and the living experience, Hayles (1999a, 291) stated, "human functionality expands because the parameters of the cognitive system it inhabits expand [...] [Therefore] it is not a question of leaving the body behind but rather of extending embodied awareness in highly specific, local, and material ways that would be impossible without electronic prosthesis." Instead of undoing bodies, we should put bodies at a central position in the studies on labouring activities particularly when bodily interactions with electronic devices are constitutive of working environment.

Beyond the interface level, no matter how geographically disperse or complicated the networks are, bodies are always at the network terminals. In the networks of information, labour, and images, human bodies are conflictive yet integrated sites for both inscriptions of cultural differences and potential interventions. The Internet is structured by hierarchical protocols and multi-layered coding system (Hayles 2004; Lessig 2006; Galloway 2001; Gallant and Boone 2011). If we see them together as a newly emerged signification mechanism, two characteristics stand out as compared with the language we use. 1) Computing systems are composed of multi-layered coding-decoding systems which centralize discursive formations and are open to individual-based interventions. 2) At stakes are not merely layers of text and coding systems, but also the physicality of the medium and the material infrastructure of the network. Internet's vast network of nodes across the world and its distributive design promise omnidirectional exchange of information. But critical Internet nodes still concentrate in a few places because the construction and maintenance need stable energy supplies and continuous updates of whatever becomes obsolescent. The access to the network comes before one can participate in the workforce online. In this sense, there are more forces at work other than just pure technological innovations or computing languages. Thus, networks are no longer neutral communication infrastructures. Instead they are deployed in regulating and controlling the labour flows and accumulations throughout the networks. More importantly, cultural differences inscribed upon (working) bodies further differentiate the social value of their labour. 
As Grosz (1994) stresses, when human is used to technological tools, tools extends human physical, psychological, and social reaches. Humans tend to forget where the devices are coming from and thus the labour embodied in the tangible technological devices is rendered invisible. Labour is objectified in the devices. Similar logic goes to social media and informational content production. Increasingly people rely upon social media to interact with each other. Social media and other smart devices become tools in their eyes, and they tend to forget about what is behind the interface. Thus, all labour, including data production labour, equipment manufacturing labour, website maintenance labour, are rendered invisible behind the interface.

It makes much more sense if we see the construction of prosumer identity as a differential technology for social division of Internet labour and compare it with the cultural representation of Chinese game play workers in the American context. Seemingly to be left out from this dominant discourse around online participatory prosumption, online gaming remains firmly in the consumption realm invoking the feelings of leisure and play in the U.S. in particular. Any productive activities and financial compensations are foreign to the gaming world except for contributions to the virtual community (that is the guild individual player belongs to in the games like the World of Warcraft). With non-monetary play set as normal behaviour, Chinese gold farmers break the rules and destroy the fun, innocent aura of the gaming space by making money out of playing without contributing to the community. American leisure players resort to racial profiling of Chinese gold farmers based on in-game behaviours and language abilities in order to protect their gaming space (Nakamura 2009; Nakamura 2012) Under these circumstances, the gaming world is not an isolated, virtual playground independent from the social reality, but part of contentious cultural realms across national borders. And the bodily inscriptions on each group, which are deeply connected to racial formations in American reality, play the role to differentiate the value of labouring bodies.

\subsection{Is spatial division of labour irrelevant to digital labour?}

Meanwhile, we must not forget that transportation advancement and international trade treaties had made it cheaper to relocate manufacturing jobs to underdeveloped countries before prominent American scholars like Daniel Bell and Fritz Machlup started to describe American society as a post-industrial society. As for the rise of network society, sociologists like Manuel Castells and Saskia Sassen explain that the formation of multi-national corporations networks, globally interdependent financial systems, and the emergence of global cities as "strategic sites" for service industries and transnational business transactions are facilitated by a variety of ICT innovations, deepened globalization, and the rise of neoliberalism which prioritizes privatization and "friction-free" market capitalism (Castells 2000; Sassen 1999; Harvey 2007). Based on his analysis of call centre workers, back-office operation, human resources and payroll management, insurance claims processors, and website services workers in India, Aneesh (2006) identifies a key shift in labour mobility in the digital age. Namely, "body-shopping" which transfers programmers to work on short-term projects overseas periodically has been replaced by online delivery of work across national borders without physical traveling. He terms them as "virtual migrant" (Aneesh 2006). Virtual migration underscores the transmission of digital labour and service via online network (virtually) and the confinement of the body within national boundaries. It enables the workers to evade such messy process as visa-applying which is unavoidable in the physical migration (read bodyshopping). However, it remains an open question whether virtual migration signals a new trend of digital labour mobility which makes geographical barriers irrelevant.

Globalization and the rise of network society are not happening evenly on the planet. And technology-triggered international division of labour does not follow the national line neatly. Some scholars recognize that the increasingly significant role played by ICT worldwide implicates a radical shift in economic organization and people's perception of space. Manuel Castells $(2000,442-453)$, for example, labelled the dominant spatial expression of the economic and cultural logic of the network society as "the space of flows", as opposed to the shared, continuous experience in a fixed place. Similarly, Michael Hardt and Antonio Negri pointed 
out that labour control in the informational age is governed by the new logic of a decentralized network, which prevails over the dependence on geographical concentration and proximity, a typical feature of labour management in the industrial manufacturing age. For white collar professionals in the developed countries, constant connectivity presents a mobile and distributed workplace which enables them to work anywhere and anytime (Gregg 2011; Rainie and Wellman 2012; Ross 2012). Geographical boundaries are not the obstacles to finish the jobs in the distributed workplace.

The reality of invisible digital labour seems to prove the opposite. Take Chinese MMORPG play workers as the example again. That China becomes the major destination of MMORPG game workers is not an accident. On contrary, the online virtual gaming world and digital labouring practice have deeply rooted in geographies. The availability of large pool of cheap labour, fast construction of the technological infrastructure, and massive influx of migrant workers from rural regions to urban areas all have paved way for cities in China and Internet cafes in the cities in particular to become the work place for game play workers (Qiu 2009). Another example is rare earth mineral miners. For example, coltan-one of the essential rare earth elements for manufacturing capacitors in laptops, mobile phones, and other electronic devices like game consoles. Although Democratic Republic of Congo possesses 80 percent of the world's coltan, its neighbouring countries like Rwanda, Uganda, and Burundi become major exploiters of coltan in Congo. Because the country has been caught in wars and violent conflicts since 1990s, the conditions of minerals mining in Congo is the "modern forms of slavery" (Fuchs 2014). Congo becomes the most tragic geographical place on the landscape of electronics manufacturing and consumption. Geography brings the country the richest natural resources but fails to bring the country an upgraded digital labour work condition. Or rather, when dominant cultural discourses help consumers in the developed countries construct digital consumption culture, mineral miners in Congo are not part of the picture. They are on the back of it. Their toils and bloody, dirty bodies are not to be seen by common prosumers in the digital age.

As shown by these examples, geography and labourers' bodies, if anything, become more important in the informational society, because geographical locations are deeply connected to information infrastructure which creates geographical segregation in the transnational labour hierarchy (Sassen 1999; Aneesh 2006; Huws 2003). Although for some workers, geographical barriers have been lifted by the technologies, institutions and policies continue erect obstacles to control labour mobility. Moreover, heterogeneous spatial transversal and border-settings accompany labour exchange, of which some become embedded in the workplace. National borders are at best selectively flexible for talented knowledge workers who frequently travel from one global city to another half-way across the planet, but become more strictly monitored for unwelcomed bodies (Sassen 2007; Sassen 1999; Ong 1999; Mezzadra and Neilson 2011).

\section{Conclusion}

When examining the relations between linguistic power and the new economy, Marazzi $(2008,42)$ argues that "the capacity for centralization and subjugation (for private appropriation) of the disseminated forces of production [...] operates now in a less directly visible and material form. It reinforces itself and subjugates by way of communicative and linguistic means, by activating symbolic and normative circuits." This article theorises digital labour by stressing discursive formations around the value of data and the value of labour in the Internet age. The cultural discourses around the potentials of (big) data and labouring activities associated with data production and consumption have been deployed by leading private companies to construct the normative behaviours in the digital realms. By reconstructing what are socially and culturally desirable activities, dominant discourses around digital labour and data have rendered certain types of labouring activities invisible, for instance, low-skilled game play workers, assembly line manufacturing workers, and so on. The feelings of fun and play and the sense of participation and sharing are among the salient features in the normative construction mechanism. Other than desirable digital labour activities, others are 
deemed as marginal and valueless, and they do not belong to the construction of digital culture. Therefore, these digital labourers who include manufacturing workers, mineral miners, and low-skilled game play workers have to be invisible. The power of these discourses not only determines varied value of data but also set new hierarchy for digital labour.

Technology in general and ICT in particular often trigger shifts in the scopes, forms, and content of work, which are almost always deployed favourably to the accumulation of capital and to disciplining workers. Technology-facilitated division of labour should be understood in the framework of social constructed differences regarding labour types and labouring bodies. Therefore, to dismantle ideological myths surrounding digital labour, scholars in particular need scrutinize the role played by cultural discourses and to be attentive to what kind of labour are invisible from the discourses and what kind of activities are constructed as highly desirable. As Fuchs (2014) forcefully argues, informational capitalism takes complex and multiple dimensions which exploits a variety of types of digital labour such as enslaved mineral miners' labour, industrial assemblage workers, as well as free social media users' labour. Indeed, it is time to deconstruct how digital capitalism works and to broaden the meaning and scope of what constitutes digital labour. More importantly, as this article argues, it is time to take into consideration the role of culture in selectively making parts of production process invisible. As we pay more attention to how culture interplays with production processes, conversations on digital labour can be broadened to talk about cultural differences constructed around different labouring bodies.

\section{Reference}

Andrejevic, Mark. 2012. Exploitation in the Data Mine. In Internet and Surveillance: The Challenges of Web 2.0 and Social Media, edited by Christian Fuchs, Kees Boersma, Anders Albrechtslund, and Marisol Sandoval, 71-88. New York, NY: Routledge.

Aneesh, A. 2006. Virtual Migration: The Programming of Globalization. Durham, N.C: Duke University Press Books.

Arvidsson, Adam, and Elanor Colleoni. 2012. Value in Informational Capitalism and on the Internet. The Information Society 28 (3): 135-50. doi:10.1080/01972243.2012.669449.

Barbrook, Richard. 2007. Imaginary Futures: From Thinking Machines to the Global Village. London: Pluto Press.

Bauwens, Michel. 2011. The Social Web and Its Social Contracts: Some Notes on Social Antagonism in Netarchical Capitalism. Re-Public: Re-Imagining Democracy. January 24. http://www.republic.gr/en/?p=261.

Beniger, James. 1986. The Control Revolution: Technological and Economic Origins of the Information Society. Boston, MA: Harvard University Press.

Benjamin, Walter. 1936. The Work of Art in the Age of Mechanical Reproduction. Marxists Internet Archive. http://www.marxists.org/reference/subject/philosophy/works/ge/benjamin.htm.

Benkler, Yochai. 2007. The Wealth of Networks: How Social Production Transforms Markets and Freedom. New Haven, CT: Yale University Press.

Boellstorff, Tom. 2010. Coming of Age in Second Life: An Anthropologist Explores the Virtually Human. Princeton, N.J: Princeton University Press.

Bohn, Roger E., and James E. Short. 2009. "How Much Information? 2009 Report on American Consumers". San Diego, CA.: Global Information Industry, University of California, San Diego Center. http://hmi.ucsd.edu/pdf/HMI_2009_ConsumerReport_Dec9_2009.pdf.

boyd, danah, and Kate Crawford. 2012. Critical Questions for Big Data. Information, Communication \& Society 15 (5): 662-79. doi:10.1080/1369118X.2012.678878.

Bruns, Axel. 2008. Blogs, Wikipedia, Second Life, and Beyond. New York: Peter Lang.

Carselle, Juan Luis. 2013. Security and Online Retailing. Interview by Paul Taylor. http://video.ft.com/2660685618001/Security-and-online-retailing/Companies.

Casaretto, John. 2012. Romney's Project Orca-A Big Data Fail. SiliconAngle. November 12. http://siliconangle.com/blog/2012/11/12/romneys-project-orca-a-big-data-fail/.

Castells, Manuel. 2000. The Rise of the Network Society (The Information Age: Economy, Society and Culture, Volume 1). 2nd ed. Cambridge, MA: Wiley-Blackwell.

Castronova, Edward. 2006. Synthetic Worlds: The Business and Culture of Online Games. Chicago: University of Chicago Press. 
Chahal, Gurbaksh. 2013. Election 2016: Marriage of Big Data, Social Data Will Determine the Next President. Innovation Insights. Accessed November 5. http://www.wired.com/insights/2013/05/election-2016-marriage-of-big-data-social-data-willdetermine-the-next-president/.

Chen, Yujie. 2013. Speculations on Bodies and Embodied Spatial Politics in the Transnational Virtual Labor Mobility: The Case of Chinese Gold Farmers. PowerLines 1 (1). http://amst.umd.edu/powerlines/yujie-chen-speculations-on-bodies/.

Chinoy, Ira. 2010. Battle of the Brains: Election-Night Forecasting at the Dawn of the Computer Age. Ph.D., United States -- Maryland: University of Maryland, College Park. http://search.proquest.com/pqdtft/docview/734386073/abstract/13AA80D09326C7346EF/1?accoun tid=14696.

Corneliussen, Hilde G., and Jill Walker Rettberg, eds. 2011. Digital Culture, Play, and Identity: A World of Warcraft $\circledast$ Reader. Boston, MA: The MIT Press.

De Angelis, M. 2001. "Marx and Primitive Accumulation: The Continuous Character of Capital's' Enclosures'." The Commoner 2: 1-22.

Dyer-Witheford, Nick. 2004. Autonomist Marxism and the Information Society. Multitudes. http://multitudes.samizdat.net/Autonomist-Marxism-and-the.html.

Fortunati, Leopoldina. 2007. Immaterial Labor and Its Machinization. Ephemera: Theory \& Politics in Organization 7 (1): 139-57.

Fuchs, Christian. 2010. Labor in Informational Capitalism on the Internet. The Information Society 26: 179-96.

— 2011. Foundations of Critical Media and Information Studies. 1st ed. New York, NY: Routledge.

2014. Theorising and Analysing Digital Labour: From Global Value Chains to Modes of Production. The Political Economy of Communication 1 (2). http://www.polecom.org/index.php/polecom/article/view/19.

Gallant, Linda M., and Gloria M. Boone. 2011. Communicative Informatics: An Active and Creative Audience Framework of Social Media. tripleC_Cognition, Communication, Co-Operation 9 (2). http://www.triple-c.at/index.php/tripleC/article/view/253.

Galloway, Alex. 2001. Protocol, Or, How Control Exists after Decentralization. Rethinking Marxism 13 (3): 81-88. doi:10.1080/089356901101241758.

Graham, Mark. 2011. Cloud Collaboration: Peer-Production and the Engineering of the Internet. In Engineering Earth, edited by Stanley D. Brunn, 67-83. Springer Netherlands. http://link.springer.com/chapter/10.1007/978-90-481-9920-4_5.

Gregg, Melissa. 2011. Work's Intimacy. 1st ed. London: Polity.

Grossberg, Lawrence. 2010. Cultural Studies in the Future Tense. Durham, NC: Duke University Press.

Grosz, Elizabeth. 1994. Volatile Bodies: Toward a Corporeal Feminism. Indianapolis: Indiana University Press.

Hardt, Michael, and Antonio Negri. 2001. Empire. Reprint. Boston, MA: Harvard University Press.

Harvey, David. 2007. A Brief History of Neoliberalism. 1st, First Edition. Oxford University Press, USA.

Hayles, N. Katherine. 1999a. How We Became Posthuman: Virtual Bodies in Cybernetics, Literature, and Informatics. 1st ed. Chicago: University Of Chicago Press.

- 1999b. How We Became Posthuman: Virtual Bodies in Cybernetics, Literature, and Informatics. 1st ed. Chicago: University Of Chicago Press.

. 2004. Print Is Flat, Code Is Deep: The Importance of Media-Specific Analysis. Poetics Today 25 (1): 67-90. doi:10.1215/03335372-25-1-67.

Horsey, David. 2012. Obama's Data Geeks Have Made Karl Rove and Dick Morris Obsolete. Los Angeles Times, November 14. http://articles.latimes.com/2012/nov/14/nation/la-na-tt-data-geeks20121113.

Hurwitz, Judith. 2012. The Making of a (Big Data) President. BusinessWeek: Companies and Industries, November 14. http://www.businessweek.com/articles/2012-11-14/the-making-of-a-big-datapresident.

Huws, Ursula. 2003. The Making of a Cybertariat: Virtual Work in a Real World. New York, NY: |Monthly Review Press.

IDC. 2011. IDC Press Release. IDC. December 1. http://www.idc.com/getdoc.jsp?containerld=prUS23177411.

Lash, Scott M. 2002. Critique of Information. 1st ed. London: Sage Publications Ltd. 
Lazzarato, Maurizio. 1999. Immaterial Labor. http://www.generationonline.org/c/fcimmateriallabour3.htm.

. 2011. Immaterial Labor. January 24. http://www.generationonline.org/c/fcimmateriallabour3.htm.

Lehdonvirta, Vili., and Mirko Ernkvist. 2011. "Converting the Virtual Economy into Development Potential: Knowledge Map of the Virtual Economy." infoDev/ World Bank.

http://www.infodev.org/en/Publication.1076.html.

Lessig, Lawrence. 2006. Code: And Other Laws of Cyberspace, Version 2.0. Basic Books.

Lovelock, Christopher H., and Robert Young. 2011. Look to Consumers to Increase Productivity. Harvard Business Review, December. http://hbr.org/1979/05/look-to-consumers-to-increaseproductivity/ar/1.

Lupton, Deborah. 2000. The Embodied Computer/User. In The Cybercultures Reader, edited by David Bell and Barbara M. Kennedy, 477-88. New York: Routledge.

Marazzi, Christian. 2008. Capital and Language: From the New Economy to the War Economy (Semiotex. New York: Semiotext(e).

Mark Zuckerberg. 2010. Facebook CEO Mark Zuckerberg: TechCrunch Interview At The Crunchies. Interview by Michael Arrington.

http://www.youtube.com/watch?v=LoWKGBloMsU\&feature=youtube_gdata_player.

Marx, Karl. 1861. Economic Works of Karl Marx 1861-1864: The Process of Production of Capital, Draft Chapter 6 of Capital, Results of the Direct Production Process. Karl Marx Internet Archive. 1863. http://www.marxists.org/archive/marx/works/1864/economic/ch02b.htm.

— _ 1995a. Capital Vol. I Chapter One: Commodities. Marx \& Engels Internet Archive. http://www.marxists.org/archive/marx/works/1867-c1/ch01.htm.

_ 1995b. Capital Vol. I Chapter Fifteen: Machinery and Modern Industry. Internet Archive. Marx \& Engels Internet Archive. http://www.marxists.org/archive/marx/works/1867-c1/ch15.htm.

McKinsey Global Institute. 2011. Big Data: The next Frontier for Innovation, Competition, and Productivity. New York, NY: McKinsey Global Institute.

http://www.mckinsey.com/insights/mgi/research/technology_and_innovation/big_data_the_next_fro ntier_for_innovation.

McRobbie, Angela. 2011. Reflections on Feminism, Immaterial Labour and the Post-Fordist Regime. New Formations 70: 60-76.

Mezzadra, Sandro, and Brett Neilson. 2011. Border as Method, Or, the Multiplication of Labor. January 24. http://eipcp.net/transversal/0608/mezzadraneilson/en.

Mitchell, Timothy. 1998. FIXING THE ECONOMY. Cultural Studies Cultural Studies 12 (1): 82-101.

Nakamura, Lisa. 2009. Don't Hate the Player, Hate the Game: The Racialization of Labor in World of Warcraft. Critical Studies in Media Communication 26 (2): 128-44.

2012. Don't Hate the Player, Hate the Game: The Racialization of Labor in World of Warcraft. In Digital Labor: The Internet as Playground and Factory, edited by Trebor Scholz, 187-204. New York, NY: Routledge.

Nardi, Bonnie. 2010. My Life as a Night Elf Priest: An Anthropological Account of World of Warcraft. Ann Arbor, MI: University of Michigan Press.

Olsthoom, Peter. 2013. It's Complicated: The Power of Facebook. Amsterdam, The Netherlands: Ehio Media.

Ong, Aihwa. 1999. Flexible Citizenship: The Cultural Logics of Transnationality. Duke University Press Books.

Oxford English Dictionary. 2013. Value, N. Oxford English Dictionary. http://www.oed.com/view/Entry/221253?rskey=TT9w5e\&result=1\&isAdvanced=false.

Pasquinelli, Matteo. 2009. Google's PageRank Algorithm: A Diagram of the Cognitive Capitalism and the Rentier of the Common Intellect. In Deep Search: The Politics of Search beyond Google, edited by Konrad Becker and Felix Stalder. Innsbruck: Studien Verlag.

Polanyi, Karl. 2001. The Great Transformation: The Political and Economic Origins of Our Time. 2nd ed. Boston, MA: Beacon Press.

Porter, Theodore M. 1995. Trust in Numbers: The Pursuit of Objectivity in Science and Public Life. Princeton, N.J.: Princeton University Press.

Poster, Mark. 1990. The Mode of Information: Poststructuralism and Social Context. 1st ed. Chicago, IL: University Of Chicago Press.

2001. What's the Matter with the Internet? 1st ed. Minneapolis, MN: Univ Of Minnesota Press. . 2004. The Information Empire. Comparative Literature Studies 41 (3): 317-34. 
Postigo, Hector. 2003. Emerging Sources of Labor on the Internet: The Case of America Online Volunteers. International Review of Social History 48 (Supplement S11): 205-23. doi:10.1017/S0020859003001329.

Prahalad, C. K., and Venkat Ramaswamy. 2004. Co-Creation Experiences: The Next Practice In.value Creation. Journal of Interactive Marketing (John Wiley \& Sons) 18 (3): 5-14.

Prodnik, Jernej. 2012. A Note on the Ongoing Processes of Commodification: From the Audience Commodity to the Social Factory. tripleC-Communication, Capitalism \& Critique 10 (2): 274-301.

Rainie, Lee, and Barry Wellman. 2012. Networked: The New Social Operating System. Cambridge, MA: The MIT Press.

Ritzer, George, and Nathan Jurgenson. 2010. Production, Consumption, Prosumption The Nature of Capitalism in the Age of the Digital 'prosumer'. Journal of Consumer Culture 10 (1): 13-36. doi:10.1177/1469540509354673.

Ross, Andrew. 2012. "In the Search of the Lost Pay Check." In Digital Labor: The Internet as Playground and Factory, edited by Trebor Scholz. New York, NY: Routledge.

Roszak, Theodore. 1987. The Cult of Information. New York, NY: Pantheon.

Sandoval, Marisol. 2013. "Foxconned Labour as the Dark Side of the Information Age: Working Conditions at Apple's Contract Manufacturers in China." tripleC: Communication, Capitalism \& Critique. Open Access Journal for a Global Sustainable Information Society 11 (2): 318-47.

Sassen, Saskia. 1999. Globalization and Its Discontents: Essays on the New Mobility of People and Money. New York: New Press, The.

2007. A Sociology of Globalization. New York: W. W. Norton \& Company.

Scherer, Michael. 2012. Inside the Secret World of the Data Crunchers Who Helped Obama Win. Time. Accessed November 9. http://swampland.time.com/2012/11/07/inside-the-secret-world-ofquants-and-data-crunchers-who-helped-obama-win/.

Scholz, Trebor, ed. 2012. Digital Labor: The Internet as Playground and Factory. New York, NY: Routledge.

Terranova, Tiziana. 2000. Free Labor: Producing Culture for the Digital Economy. Social Text 63 (18): 33-58.

- 2004. Network Culture: Politics for the Information Age. London: Pluto Press.

The Economist. 2010. Data, Data Everywhere (Special Report: Managing Information). The Economist, February 25. http://www.economist.com/node/15557443.

The World Bank. 2012. Global Economy Prospects. Washington, DC: The World Bank. http://web.worldbank.org/WBSITE/EXTERNAL/EXTDEC/EXTDECPROSPECTS/EXTGBLPROSPE CTSAPRIL/0,,menuPK:659178 pagePK:64218926 piPK:64218953 theSitePK:659149,00.html.

Thrift, Nigel. 2006. Re-Inventing Invention: New Tendencies in Capitalist Commodification. Economy and Society 35 (2): 279-306. doi:10.1080/03085140600635755.

Turkle, Sherry. 1997. Life on the Screen: Identity in the Age of the Internet. First Edition. New York, NY: Simon \& Schuster.

United States Securities and Exchange Commission. 2012. Registration Statement on Form S-1 by Facebook Inc. United States Securities and Exchange Commission. http://sec.gov/Archives/edgar/data/1326801/000119312512034517/d287954ds1.htm.

Van Dijck, J., and D. Nieborg. 2009. Wikinomics and Its Discontents: A Critical Analysis of Web 2.0 Business Manifestos. New Media \& Society 11 (5): 855-74. doi:10.1177/1461444809105356.

Virno, Paolo. 2004. A Grammar of the Multitude: For an Analysis of Contemporary Forms of Life (Semiotex. Translated by Isabella Bertoletti, James Cascaito, and Andrea Casson. First US edition. New York, NY: Semiotext(e).

Vos, Dan. 2012. Big Data Spells Death-Knell for Punditry. The Guardian. November 7. http://www.guardian.co.uk/media-network/media-network-blog/2012/nov/07/big-data-us-electionsilver.

Weeks, Kathi. 2011. The Problem with Work: Feminism, Marxism, Antiwork Politics, and Postwork Imaginaries. Durham, NC: Duke University Press Books.

Weinberger, David. 2012. Too Big to Know: Rethinking Knowledge Now That the Facts Aren't the Facts, Experts Are Everywhere, and the Smartest Person in the Room Is the Room. New York, NY: Basic Books.

Yee, Nick. 2006. The Labor of Fun: How Video Games Blur the Boundaries of Work and Play. Games and Culture 1 (1): 68-71. doi:10.1177/1555412005281819. 


\section{About the Author}

\section{Yujie Chen}

Yujie Chen (chenyj@umd.edu) is Ph.D. candidate in American Studies at the University of Maryland, College Park. Her research interest includes digital labour, big data culture, and critical digital media studies. Her dissertation explores how labour is rendered invisible in the ideologies around Big Data and argues to redefine the concept of digital labour for the age of data glut. She teaches courses on diversity and changing cultures of work and play in the digital age. 